\title{
TITLE:
}

\section{Ontogeny of a social custom in wild chimpanzees: age changes in grooming hand-clasp at Mahale}

\author{
$\operatorname{AUTHOR}(\mathrm{S})$ :
}

Nakamura, Michio; Nishida, Toshisada

\section{CITATION:}

Nakamura, Michio ...[et al]. Ontogeny of a social custom in wild chimpanzees: age changes in grooming hand-clasp at Mahale. American journal of primatology 2013, 75(2): 186-196

\section{ISSUE DATE:}

2013-02

URL:

http://hdl.handle.net/2433/173370

\section{RIGHT:}

(c) 2012 Wiley Periodicals, Inc.; この論文は出版社版でありません。引用 の際には出版社版をご確認ご利用ください。; This is not the published version. Please cite only the published version. 
NOTICE: This is the author's version of the following article.

Nakamura M, Nishida T 2013. Ontogeny of a social custom in wild chimpanzees: Age changes in grooming hand-clasp at Mahale. Am J Primatol 75:186-196. DOI 10.1002/ajp.22098

(C) Wiley Periodicals, Inc.

\title{
Ontogeny of a Social Custom in Wild Chimpanzees: Age Changes in Grooming Hand-Clasp at Mahale
}

\author{
MICHIO NAKAMURA $^{1 *}$ AND TOSHISADA NISHIDA $^{2 \dagger}$
}

\author{
${ }^{1}$ Kyoto University, Kyoto, Japan \\ ${ }^{2}$ Japan Monkey Centre, Aichi, Japan \\ *Correspondence to: Michio Nakamura, Wildlife Research Center, Kyoto University, 2-24, Tanaka-Sekiden-Cho, \\ Sakyo, Kyoto 606-8203, Japan. E-mail: nakamura@wrc.kyoto-u.ac.jp \\ ${ }^{\dagger}$ Deceased.
}

\begin{abstract}
Among cultural behaviors of chimpanzees, the developmental processes of complex skills involved in tool use are relatively well known. However, few studies have examined the ontogeny of social customs that do not require complex skills. Thus, in this study, we describe the developmental process of the grooming hand-clasp (GHC), one of the well-known social customs of chimpanzees at Mahale. We have collected 383 cases of GHC where at least one of the participants was 15 years old or younger during 1994-2007. First performances of GHC with the mother were observed at around 4-6 years old; the earliest observed age was 4 years and 4 months old. The first performances of GHC with nonrelated females were at around age 9 years, and those with adult males at around 11 years. However, some orphans engaged in GHC earlier than nonorphans. By gradually expanding GHC partners from the mother to other females and then to males, chimpanzees increased the number of GHC partners with age. Young males were observed to perform GHC with larger numbers of partners than were young females. GHC by young chimpanzees was shorter in duration than that among adults. Overall, the ontogeny of GHC showed several dissimilarities with that of tool use and was more an extension of the development of typical grooming behavior. For example, infants did not try to perform GHC initially; instead, mothers were more active in the earliest stages. These results suggest that not all socially learned cultural behaviors are acquired in the way of learning tool use. There may be various ways of learning behavioral patterns that are performed continuously in a group and that consequently comprise culture in chimpanzees.
\end{abstract}

Key words: chimpanzee; grooming hand-clasp; social custom; culture; learning process

\section{INTRODUCTION}

Accumulated knowledge demonstrates that the behavioral repertoires of some nonhuman animals differ considerably among groups or among populations without apparent ecological or genetic explanations for these differences [e.g., chimpanzees: Whiten et al., 1999; cetaceans: Rendell \& Whitehead, 2001; capuchin monkeys: Panger et al., 2002; Perry et al., 2003; orangutans: van Schaik et al., 2003; bonobos: Hohmann \& Fruth, 2003]. The chimpanzee (Pan troglodytes) is best known for such behavioral diversity in terms of the breadth (number of research sites) and depth (history of the research) of our knowledge. In addition to such knowledge from wild populations, more controlled experimental studies of chimpanzees in captivity have shown that chimpanzees are capable of learning novel behaviors socially [e.g., Bonnie et al., 2007; Whiten et al., 2005, 2007]. These findings indicate that some of this behavioral diversity in the wild can be considered, at least by some scholars, socially learned culture.

However, considerable debate exists over whether such behavioral diversity can be considered synonymous with human culture and over how to define animal culture [Boesch, 1996; Boesch \& Tomasello, 1998; Byrne et al., 2004; Fragaszy \& Perry, 2003; Galef, 1992; Krützen et al., 2006; Laland \& Janik, 2006; McGrew, 2004; Tomasello, 1994; Whiten \& van Schaik, 2007; also see Laland \& Galef, 2009 for an overview of various opinions]. For example, Laland and Janik [2006] critiqued the methodology used by Whiten et al. [1999] (synonymous to the "method of exclusion" of Krützen et al. [2006]) arguing that this method does not exclude possible as-yet-unknown genetic or ecological differences and may therefore cause noncultural (i.e., not socially learned) behaviors to be considered cultural. Recently, Langergraber et al. [2011] showed that some behaviors listed by Whiten et al. [1999] were correlated with genetic differences and argued that genetic differences cannot be ruled out as playing a major role in generating differences in behavior [but see Lycett et al., 2011, for a different interpretation of the results]. Kamilar and Marshack [2012] 
used the same behavioral list to investigate the relative importance of geographic and ecological variables, where they found that behavioral variation was best explained by longitude, but not by local ecology. However, it is reported that at least some (but no all) of the differences in ant-dipping techniques were well explained by ecological factors (such as aggressiveness of the target ants) [Humle \& Matsuzawa, 2002; Möbius et al., 2008; Schöning et al., 2008]. The debate continues, and the conclusion may be that such behaviors are attributable to some complex mixture of genetic, ecological, social, and cultural determinants.

One thing that field primatologists can provide in terms of the understanding of chimpanzee behavioral diversity is how such cultural behaviors are maintained in a group through generations, that is, how and when a naïve young individual acquires such behaviors. Although it is almost impossible to follow an individual in the wild from its birth to the acquisition of a particular behavior without interruption, it is important to accumulate knowledge of general patterns with respect to how and when young chimpanzees in their natural environment start to perform a particular cultural behavior.

\section{Social Customs in Chimpanzees}

The most well-known and well-studied representative of chimpanzee culture is their material culture, as represented by various kinds of tool use [Mc- Grew, 1992]. In their landmark paper, Whiten et al. [1999] listed 39 behaviors as cultural; among them, 37 involved some kind of object manipulation, and 16 involved tool use to obtain foods. However, later studies found more and more differences in social and other nontool behaviors, such as grooming, greeting, courtship display, and play [e.g., Nakamura \& Nishida, 2006; Nakamura et al., 2000; Nishida \& Wallauer, 2003; Nishida et al., 2004].

The grooming hand-clasp (GHC) is one such social custom that differs among populations but does not require the use of materials. This behavioral pattern was first reported by McGrew and Tutin [1978] in Mahale K group (now extinct) chimpanzees. Mahale M group chimpanzees also showed an identical grooming pattern [Nakamura, 2002], although some intergroup or interindividual variation was suggested [McGrew et al., 2001; Nakamura \& Uehara, 2004]. In GHC, two individuals sit face-to-face, each clasping the other's corresponding hand or crossing wrists (either right-right or left-left) overhead, and grooming the partner's underarm region simultaneously with the remaining hands [see Nakamura, 2002 for photo]. In Mahale M group, this behavior was mostly performed by adult and late adolescent members of both sexes and was observed on average once per $5.1 \mathrm{hr}$ of observation [Nakamura, 2002].

GHC occurs as a customary pattern (i.e., performed by the majority of members of some age-sex classes in a group) in some populations of chimpanzees, but does not occur at all in others [see Nakamura, 2002, for the distribution of GHC]. The distribution is not apparently directly connected with subspecies differences or geographical distances. An identical pattern has also been observed in some captive chimpanzee colonies and sanctuaries [Bonnie \& de Waal, 2006; de Waal \& Seres, 1997; Humle et al., 2009a; van Leeuwen et al., 2012].

\section{Development of Cultural Behaviors}

Many reports have described the acquisition process for tool use. In many types of tool use, the first successful performance by an infant is usually at 2-3 years old [termite-fishing: Lonsdorf, 2005; van LawickGoodall, 1970; arboreal ant-fishing: Nishida \& Hiraiwa, 1982; Nishie, 2011; driver ant-dipping: Boesch \& Boesch-Achermann, 2000; Humle et al., 2009b; McGrew, 1977; nut-cracking: Matsuzawa, 1994]. It seems that the more difficult the task is (such as nut-cracking that requires the use of two tools), the later the successful use of tools occurs. Also, the acquisition time may be delayed in accordance with the characteristics of the target object (e.g., successful use of tools for nut-cracking appears later when the target nut species is harder [Boesch \& Boesch-Achermann, 2000]).

Although there are subtle differences, overall, the acquisition of tool use has several common features:

(1) At the earliest stage (before acquisition of tool use), an infant begins to show interest in its mother or other adults as they use tools nearby. For example, an infant reaches for a tool being used by the mother or watches carefully from a close distance.

(2) The mother or other adults are usually tolerant of such interest and, sometimes, disturbances by the infant, but active teaching, such as demonstration, is rare.

(3) Trials by the infant include rudimentary and inappropriate actions, such as trying to poke an ant nest with an index finger or hitting a nut with a bare hand. Such trials are often made in a playful manner.

(4) Even though no rewards follow these initial trial efforts, such trial-and-error learning continues for a long time (a few years) until the appropriate way of using the tool is finally acquired.

There are also some exceptions to this procedure. Although active teaching is rare, two cases of teaching by a mother were reported from Taï [Boesch, 1991]. Playful trials were not involved in the acquisition of ant-dipping at Gombe, probably because inappropriate manipulation might cause considerable pain due to ant bites [McGrew, 1977]

In addition to these observation from the wild, experimental introductions of novel tool use in captivity have yielded similar results: the mother and other adults served as important models for infants, infants sometimes reached for tools, adults were very tolerant of such actions, and no active teaching was observed [Hirata \& Celli, 2003]. In sum, close observation and tolerance based on affiliative relationships between the model and the learner and successive trial-and-error 
efforts may be important for the acquisition of tool use, rather than imitation or teaching. Usually, the mother is the most important model [Humle et al., 2009b; Lonsdorf, 2005], and the infant, with strong motivation to be like the model, performs several trials in a playful and rudimentary manner. Such learning was called bonding- and identification-based observational learning (BIOL) by de Waal [2001] or master-apprenticeship learning by Matsuzawa et al. [2001] and seems to be generally applicable to chimpanzees' acquisition of relatively complex skills such as tool use.

On the other hand, few reports have examined how social customs other than tool use are acquired. Although a few studies successfully showed the spread of nontool behaviors in captivity [Bonnie et al., 2007; Hopper et al., 2011], such behaviors still have some similarity with tool use in that the final goals were to obtain food and the goals were accomplished with the mediation of objects (tokens, in these studies). The acquisition process of social customs may be similar to that of tool use in the sense that both are learned socially. However, there may be differences because the behavioral patterns of many social customs are not as complex and require no particular skill. For example, the motor patterns required for GHC are simply to raise and clasp one arm and to groom the partner. However, unlike tool use, which can be performed alone, social behaviors such as GHC always require a partner; thus, different elements may be more important, such as social context, timing, or coordination with the partner. Such differences may result in different acquisition processes from those found in tool use.

The main aim of this study was to describe the general ontogeny of GHC based on long-term observations. We first describe the first observed ages of emergence of GHC in young chimpanzees, differences between sexes, and age changes in GHC duration and partners. These results are compared with the learning model described above for tool use and with the general developmental pattern of typical grooming.

\section{METHODS}

The subjects of this research were the wild chimpanzees of M group in the Mahale Mountains National Park, Tanzania [see Nishida, 1990, 2012, for details of the research site]. All chimpanzees were fully habituated to human observers and named individually. Abbreviated names are used throughout the paper, and those of females are italicized. Data for 13 years, from 1994 to 2007 (except 1995 when no field observation was made), were analyzed, including data taken with focal follows of individuals and/or subgroups. The main data set consists of 383 cases of GHC (Table I) in which at least one of the participants was 15 years old or younger (i.e., infants to adolescents for males [Hiraiwa-Hasegawa et al., 1984]). Females are usually regarded as adults when they are 13 years old [Hiraiwa-Hasegawa et al., 1984], but we also included data of females up to 15 years old in correspondence to males. For the convenience, we use a term "youngsters,” slightly irregular usage to include adult females, to refer to individuals of 15 years or younger for both sexes. We also included data of GHC among those 16 years or older to compare the duration of GHC.

We know from experience that GHC by young chimpanzees is very rare at Mahale. For example, in $451.7 \mathrm{hr}$ of focal follows of adolescent males, focal chimpanzees performed only five instances of GHC ( 0.011 times/hr or once per $90.3 \mathrm{hr}$ ), and only three of nine focal males performed it at all [Nakamura, unpublished data]. As GHC by infants and juveniles is expected to occur at an even lower frequency, it was not realistic to collect GHC data with a focal sampling method on youngsters. Thus, we conducted all-occurrence sampling of GHC by recording all the observed GHC even during follows of other individuals or subgroups. Because GHC is a conspicuous behavioral pattern that last for several to several tens of seconds, it seems unlikely that it would be missed when it occurs within the visual range of the observers.

Due to the nonnormal distribution and small sample size of the data set, we employed nonparametric statistical tests. All the statistical analyses were conducted using the $\mathrm{R}$ software ( $\mathrm{R}$ version 2.12.1) and were considered significant when $\mathrm{P}<0.05$ in two-tailed tests.

Our methods adhered to the guidelines and principles of the American Society of Primatologists for the ethical treatment of nonhuman primates. All field protocols and data-collection procedures were strictly observational and conducted in accordance with wildlife study guidelines, ethical standards, and regulations of the Wildlife Research Center of Kyoto University, Japan, the Tanzania Wildlife Research Institute, and the Tanzania National Parks, Tanzania.

\section{RESULTS}

\section{GHC by Individuals 15 Years Old or Younger}

Table I lists all 383 cases of GHC by youngsters (chimpanzees 15 years old or younger). No GHC by individuals 3 years old or younger was observed. After 4 years old for males and 5 years old for females, GHC was observed at all ages. Of the 383 cases, 295 involved males, and 88 involved females as younger participants. Compared with the average number of males (12.08) and females (18.46) in these age groups during the study period, the sex difference was significantly biased toward males (chi-squared test for given probabilities: $\chi^{2}=225.0, \mathrm{df}=1, \mathrm{P}<0.001$, expected probabilities were calculated from 12.08:18.46). The sex difference was also significant when we compared GHC by corresponding ages of males and females (4-15 years old: Wilcoxon matched-pairs signed-rank test: $\mathrm{N}=12, \mathrm{~T}=75, \mathrm{P}<0.005)$. Mean number of GHC per individual increased with age for males $(4-15$ years old: Kendall's rank correlation test: $\mathrm{N}=12, \tau=0.66$, $\mathrm{P}<0.01$ ), but no such tendency was seen in females $(\mathrm{N}=12, \tau=0.31, \mathrm{P}=0.17)$.

\section{GHC Partners}

Figure 1 shows GHC partners of youngsters in each year. Until 7 years old, all the observed partners for males were their mothers (shown as " $M$ " in Fig. 1). The 
same was true for females, except for orphans; orphaned females (ME, PF, and PP) at this age performed GHC with nonrelated females, and the partner for two (PF and PP) was the same old female, GW, who adopted them in different periods.

Around 8-9 years old, youngsters started to perform GHC with females other than their own mothers (shown as "O+" in Fig. 1). Two males (OR and DW) did so when they were 8 years old. The partner of OR was his older sister and the partner of DW (who was an orphan) was an unrelated female. The earliest GHC with nonrelated females by nonorphaned males was observed at 9 years old, by XM, PR, CD, and PM. Nonorphaned natal females were not observed to engage in GHC with females other than their mothers until they were 14 years old.

GHC with adult males was last to appear. CL performed GHC with an adult male when he was 9 years old, and DW when he was 10 years old. However, again, these two males were orphans. A nonorphan, CD, also performed GHC with an adult male at the age of 10 , but the partner was a related male, his older brother. Thus, the earliest age at which a nonorphaned male performed GHC with a nonrelated adult male was 11 years old (PR). Others did not do so until the age of 13-15 years (late adolescence). Females were not observed to engage in GHC with adult males until they were adults themselves. The immigrant females commenced GHC in the new group with adolescent males.

As described above, youngsters performed GHC mainly with their mothers when young and then started to do so with individuals of various age-sex classes as they matured (Fig. 2). As a consequence, the relative proportion of GHC with the mother declined significantly with age (4-15 years old: $\mathrm{N}=12, \tau=-0.73$, $\mathrm{P}<0.001$ ), and the average number of GHC partners increased with age (4-15 years old: $N=12, \tau=0.79$, $\mathrm{P}<0.001$, Fig. 3). When we compared the number of partners in corresponding age groups, males had significantly more partners than their age-mate female peers (4-15 years old: Wilcoxon matched-pairs signed-rank test: $\mathrm{N}=12, \mathrm{~T}=61, \mathrm{P}<0.05$ ).

\section{Duration of GHC}

Including instances of GHC among individuals 16 years old or older, we recorded 696 cases that were observed completely from start to end. Among these, the median duration of GHC by the oldest age class (16 years or older) was $32.0 \mathrm{sec}(\mathrm{N}=353)$, that by the middle age class (10-15 years old) was $25.0 \mathrm{sec}(\mathrm{N}=218)$, and that by the youngest age class ( 9 years old or younger) was $18.0 \mathrm{sec}(\mathrm{N}=125$; Fig. 4). Duration differed significantly among these classes (Kruskal-Wallis test, $\chi^{2}=57.8, \mathrm{df}=2, \mathrm{P}<0.001$ ) with significant differences between all age-group combinations (Sheffe's multiple comparison, $\mathrm{P}<0.001$ ).

\section{First Performances of GHC and Related Behaviors}

Three cases were observed that could be interpreted as infants observing the GHC performances of their mothers. Three infants (PI98 when she was 6 months old, MC when he was 8 months old, and FV when she was 1 year and 4 months old) climbed the arms of their mothers performing GHC, and the infants watched the clasped hands.

The first observed performances of GHC with the mother are listed in Table II. Although the sample size was small and we cannot be sure that these were really the individual's first performances, mothers initiated most of these early instances of GHC, at least in the cases observed. In the case of XM, his mother, XT, not only initiated but also molded [sensu "molding" in Nishida 2003: p 403] his hand to the posture of GHC (Fig. 5). Similar molding behaviors were observed by XT toward XM (again, at 5 years and 5 months), by PI toward her son PR (three times when PR was 9 years and 4 months and twice when he was 10 years and 5 months old), and by GW toward her adopted daughter PP (once each at 6 years and 7 months, 9 years and 3 months, and 10 years and 3 months). Three additional cases of unsuccessful molding by mothers were observed (by MJ toward her son MC at 4 years and 2 months and at 4 years and 3 months, and by XT toward her son XM at 4 years and 4 months) in which mothers molded the GHC posture, but sons did not respond with grooming.

On the other hand, offspring was never observed to request that the mother perform GHC (such as pulling mother's hand or molding her posture), even in a rudimentary manner, nor to do anything that could be considered learning trials for GHC. Infants and juveniles were never observed to engage in GHC with one another, even in playful ways; that is, adults or adolescents were always the partners for individuals in these two youngest age classes.

\section{DISCUSSION}

Starting Age of GHC

The first GHC with mother was at about 4-6 years old. It is possible that this may be slightly overestimated because we could not exclude the possibility that earlier GHC was not witnessed. However, it is important to note that not a single case of GHC by individuals 3 years old or younger was observed during this long-term observation. Nor was it observed during another earlier study with an intense focus on the development of social grooming, during which the earliest observed age of GHC was 5.7 years old [Nishida, 1988]. Thus, although most tool use starts at $2-3$ years of age, it seems likely that the starting age for GHC is later (Table III).

GHC with nonrelated females was first observed in an orphaned female at 5 years and 4 months old, but for the most part, it seemed to start at about the age of 9 years if the offspring's mother was still alive. GHC with adult males came last, and a nonorphaned male first did this at the age of 11 years. It is difficult to believe that such a late start of GHC with nonrelated individuals is due to any lack of knowledge or skills. It may just reflect the general grooming partners for each developmental stage (see Comparisons with Development of Typical Grooming). GHC with nonrelated individu- 
als started earlier in orphans than in nonorphans. Such earlier social development of orphans is consistent with other social behaviors, such as association and general grooming [Hayaki, 1988].

It is not surprising that the number of GHC partners increased with age. The results from this study show that youngsters, at least males, expanded GHC partners from their mothers to nonrelated females and then to adult males as they became older. When they became adults, they performed GHC with adult males and females.

The shorter duration of GHC among younger individuals is also not surprising. Because youngsters always perform GHC with older individuals, the posture may be asymmetric due to the smaller body sizes of the youngsters. Also, because youngsters have less physical strength in their arms, it may be difficult for them to hold their arms in an upright position for a long time.

\section{Sex Differences}

The starting age for GHC with the mother (or adopted mother in the case of orphans) did not seem to differ between the sexes. However, young males were observed to do GHC more and to have more partners than their female counterparts. This is interesting because there was no sex difference in performance of GHC by adults [see Nakamura, 2002; Table 5.3], and the number of GHC partners did not seem to differ by sex during this study period (e.g., the one with most partners was adult male DE with 25 partners, but the second two were females, MJ and GW, both of whom had 23 partners). Thus, the sex difference in GHC found in youngsters was not a simple predictor of the adult pattern. This differs from tool use in that sex differences in the early period of tool use are usually good indicators of adult sex differences. For example, females learn termite-fishing earlier than do males in Gombe [Lonsdorf, 2005], and this can be related to the adult sex difference of termite-fishing; it is more often performed by females than males [McGrew, 1979]. No sex difference was found in the onset of ant-dipping at Bossou [Humle et al., 2009b], which is again consistent with the adult pattern, as ant-dipping is performed equally by both sexes.

One possible explanation for sex differences in observed GHC may be observation biases toward males because males in their adolescence start to associate with adult males, usually in a large subgroup [Hayaki, 1988; Pusey, 1983]. However, because we also followed female offspring and their mothers, it is not explained solely by such observation bias because not a single GHC with nonrelated individuals was observed in nonorphaned young females. Because males continue to stay in their natal unit-group, whereas most females transfer to different groups at adolescence, it may be beneficial for males to create a wider social network in adolescence, whereas it may not be so important for females to do so.

Comparison with Process of Learning Tool Use

It is common in both GHC and tool use that the mother plays a primary and important role in the acquisition of behaviors. However, the importance of the mother in GHC seemed to lie in being a first partner, whereas the mother's role in tool use is basically as a model. Thus, infants observe mother's tool use intensely and frequently [Matsuzawa, 1994; van Lawick-Goodall, 1970] and when a mother uses tools more frequently (i.e., serves as a model more often), her offspring acquire tool use more quickly [Humle et al., 2009b]. Probable interest in and observations of GHC by infants of 0 - to 1-year old were also observed for this behavior, but they occurred with much lower frequency. Thus, although it is possible that mothers also serve as models in GHC, the connection between such interest/observation and acquisition was unclear because there were no subsequent trials by such infants.

There are more dissimilarities than similarities; first, the starting age of GHC was much later than that for most tool use. This may seem strange if we consider acquisition of cultural behaviors only in terms of learning necessary skills. Because GHC does not require complex skills, it should have been acquired much earlier. Acquisition of complex skills does matter in tool use, but there seem to be different limiting factors in the acquisition of GHC.

Second, there were no rudimentary and/or playful trials during the process of GHC acquisition by the infant. Such trials are very common in the acquisition of tool use [Matsuzawa, 1994; van Lawick-Goodall, 1970], probably connected with the offspring's high motivation. Because tool use is often related to obtaining food, the offspring may be able to understand the outcome and to maintain a high motivation to do as their mothers do, even without efficiently obtaining a reward in the short term. On the other hand, in GHC, the offspring's motivation does not seem so high, probably because there is no direct reward to the offspring for performing it.

Finally in connection with the second point, the ontogeny of GHC differs from that of tool use in that the mother, not the offspring, seems to play the more active role in the early performance by the offspring. The most obvious case is the practice of molding, which directly invites the offspring to the form of GHC. However, we do not conclude that it is a kind of active teaching [Caro \& Hauser, 1992] in the strict sense because molding did not always accompany the observed first performances of GHC; on the contrary, it was sometimes directed toward offspring who had performed GHC before. However, it is doubtful that XM would have performed GHC at such early age without his mother's molding. It should be noted that his was the youngest age among all observed cases of GHC by the Mahale chimpanzees so far. Molding may not be a necessary condition for acquisition of GHC, but it seems likely that if the mother is more active in inviting the offspring to participate, they may begin to do it earlier than those without mothers' active invitation.

To summarize, the acquisition of GHC and tool use have in common that the mother plays an important role, in a broad sense. However, the form of learning 
underlying GHC in Mahale seems to differ largely from the learning mechanisms of tool use proposed in BIOL [de Waal, 2001] or the master- apprenticeship model [Matsuzawa et al., 2001].

\section{Comparisons with Development of Typical Grooming}

It seems that the development of GHC can be understood as an extension of that of usual (i.e., nonGHC) grooming behaviors. The earliest age for an infant to groom its mother is 10 months old, and at the age of 2, half of the infants did so at Mahale [Nishida, 1988]. If we compare these ages with the starting age of GHC, the latter is far later. However, the earliest observed age of simultaneous mutual grooming with the mother was at 3 years and 8 months for females and 4 years and 9 months for males [Nishida, 1988]; this did not differ from that of GHC, at least for males. Thus, the limiting factor in GHC may be grooming mutually (simultaneously) with the mother, and when that is achieved, GHC can occur with little time lag. Even though the mother was active in the early occurrence of GHC, the mother may not have any intention to teach the cultural behavior to her naïve offspring; rather, she may just be interacting with her offspring who are old enough to groom mutually and thus to reciprocate grooming in the way she habitually does with others (i.e., in the form of GHC).

Sex differences found in GHC partners may be explained by the sex difference in the usual grooming partners in juveniles and adolescents. Although males of these ages groomed partners of all age-sex classes, females only groomed their mothers and siblings at Gombe [Pusey, 1990]. Similarly, the late occurrences of GHC with adult males may be explained by usual grooming patterns because early adolescent males were groomed by adult females, but rarely by adult males [Pusey, 1990]. GHC cannot be performed if adult males do not engage at all in reciprocal grooming with young males. Also, the increase in GHC frequency with age corresponds with the fact that usual grooming frequency by males increased between 5 and 20 years of age at Mahale [Hayaki, 1992].

GHC has been observed at Mahale for several decades but has never been performed by Gombe chimpanzees, although they belong to the same subspecies and live only about $150 \mathrm{~km}$ from Mahale. Thus, GHC has been listed among cultural behaviors together with many types of tool use [Whiten et al., 1999]. Although the same name "culture" is applicable to both GHC and tool use, the underlying mechanisms of their learning seem to differ largely. The performance and acquisition of GHC do not seem to be related much to the transfer of skills. GHC seems to be acquired as an extension of usual grooming practices, one of the universal chimpanzee acts. Thus, Mahale chimpanzees may not be performing GHC as a special "culture.” This is perhaps similar to some human social customs: the Japanese children do not explicitly learn "bowing" as a special form of greeting within a Japanese community (unlike the use of chopsticks, which they have to learn inten- tionally). They notice, when they go abroad, that Western people do not bow in greeting.

GHC may be acquired by the young chimpanzees at Mahale simply as a form of grooming or a casual social interaction. However, such casual acquisition of a behavior actually leads to differences that continue to exist between Mahale and Gombe. If we accept that culture is not simply composed of material culture but is a complex mixture of several types of behaviors and interactions, it is essential to see how different learning processes underlie such different cultural behavioral patterns to gain a better understanding of chimpanzee culture.

\section{ACKNOWLEDGMENTS}

We thank the Tanzania Commission for Science and Technology (COSTECH), the Tanzania Wildlife Research Institute (TAWIRI), the Tanzania National Parks (TANAPA), the Mahale Mountains Wildlife Research Centre (MMWRC), and the Mahale Mountains National Park (MMNP) for permission to do this research. We also thank Dr. W. C. McGrew and an anonymous reviewer for comments on the manuscript. The study was supported by grants from the Japanese Ministry of Education, Culture, Sports, Science and Technology (\#19255008 to TN, \#19107007 to J. Yamagiwa, and \#21770262 to MN). The second author, Prof. Toshisada Nishida, passed away in June 2011 while we were preparing the manuscript. MN would like to express the deepest condolence on his untimely death.

\section{REFERENCES}

Boesch C. 1991. Teaching among wild chimpanzees. Anim Behav 41:530-532.

Boesch C. 1996. Three approaches for assessing chimpanzee culture. In: Russon AE, Bard KA, Parker ST, editors. Reaching into thought. Cambridge: Cambridge University Press. p 404-429.

Boesch C, Boesch-Achermann H. 2000. The chimpanzees of the Taï Forest. Oxford: Oxford University Press.

Boesch C, Tomasello M. 1998. Chimpanzee and human cultures. Curr Anthropol 39:591-614.

Bonnie KE, de Waal FBM. 2006. Affiliation promotes the transmission of a social custom: handclasp grooming among captive chimpanzees. Primates 47:27-34.

Bonnie KE, Horner V, Whiten A, de Waal FBM. 2007. Spread of arbitrary conventions among chimpanzees: a controlled experiment. Proc R Soc B 274:367-372.

Byrne RW, Barnard PJ, Davidson I, Janik VM, McGrew WC, Miklosi A, Wiessner P. 2004. Understanding culture across species. Trends Cogn Sci 8:341-346.

Caro TM, Hauser MD. 1992. Is there teaching in nonhuman animals? Q Rev Biol 67:151-174.

de Waal F. 2001. The ape and the sushi master. New York: Basic Books.

de Waal FBM, Seres M. 1997. Propagation of handclasp grooming among captive chimpanzees. Am J Primatol 43:339-346.

Fragaszy DM, Perry S. 2003. Towards a biology of traditions. In: Fragaszy DM, Perry S editors. The biology of traditions. New York: Cambridge University Press. p 1-32.

Galef BG, Jr. 1992. The question of animal culture. Hum Nat 3:157-178.

Hayaki H. 1988. Association partners of young chimpanzees in the Mahale Mountains National Park, Tanzania. Primates 
29:147-161.

Hayaki H. 1992. Grooming partners of young males in a chimpanzee unit-group at the Mahale Mountains National Park, Tanzania. Bull Fac Hum Sci Kobe Gakuin Univ 4:83-105 (in Japanese).

Hiraiwa-Hasegawa M, Hasegawa T, Nishida T. 1984. Demographic study of a large-sized unit-group of chimpanzees in the Mahale Mountains, Tanzania: a preliminary report. Primates 25:401-413.

Hirata S, Celli ML. 2003. Role of mothers in the acquisition of tool-use behaviours by captive infant chimpanzees. Anim Cogn 6:235-244

Hohmann G, Fruth B. 2003. Culture in bonobos? Between species and within-species variation in behavior. Curr Anthropol 44:563-571.

Hopper LM, Schapiro SJ, Lambeth SP, Brosnan SF. 2011. Chimpanzees' socially maintained food preferences indicate both conservatism and conformity. Anim Behav 81:1195-1202.

Humle T, Colin C, Raballand E. 2009a. Preliminary report on hand-clasp grooming in sanctuary-released chimpanzees, Haut Niger National Park, Guinea. Pan Africa News 16:7-10.

Humle T, Matsuzawa T. 2002. Ant-dipping among the chimpanzees of Bossou, Guinea, and some comparisons with other sites. Am J Primatol 58:133-148.

Humle T, Snowdon CT, Matsuzawa T. 2009b. Social influences on ant-dipping acquisition in the wild chimpanzees (Pan troglodytes verus) of Bossou, Guinea, West Africa. Anim Cogn 12:S37-S48.

Inoue-Nakamura N, Matsuzawa T. 1997. Development of stone tool-use by wild chimpanzees (Pan troglodytes). J Comp Psychol 111:159-173.

Kamilar JM, Marshack JL. 2012. Does geography or ecology best explain 'cultural' variation among chimpanzee communities? J Hum Evol 62:256-260.

Krützen M, van Schaick C, Whiten A. 2006. The animal culture debate: response to Laland and Janik. Trends Ecol Evol 22:6. Available online at:

http://dx.doi.org/10.1016/j.tree.2006.10.011. [Accessed on 10 November 2006]

Laland KN, Galef BG, editors. 2009. The question of animal culture. Cambridge, MA: Harvard University Press.

Laland KN, Janik VM. 2006. The animal cultures debate. Trends Ecol Evol 21:542-547.

Langergraber KE, Boesch C, Inoue E, Inoue-Murayama M, Mitani JC, Nishida T, Pusey A, Reynolds V, Schubert G, Wrangham RW, Wroblewski E, Vigilant L. 2011. Genetic and 'cultural' similarity in wild chimpanzees. Proc R Soc B 278:408-416.

Lonsdorf EV. 2005. Sex differences in the development of termite-fishing skills in the wild chimpanzees, Pan troglodytes schweinfurthii, of Gombe National Park, Tanzania. Anim Behav 70:673-683.

Lycett SJ, Collard M, McGrew WC. 2011. Correlation between genetic and behavioural dissimilarities in wild chimpanzees (Pan troglodytes) do not undermine the case for culture. Proc R Soc B 278:2091-2093.

Matsuzawa T. 1994. Field experiments of use of stone tools in the wild. In: Wrangham RW, McGrew WC, de Waal FBM, Heltne PG, editors. Chimpanzee cultures. Cambridge. MA: Harvard University Press. p 351-370.

Matsuzawa T, Biro D, Humle T, Inoue-Nakamura N, Tonooka R, Yamakoshi G. 2001. Emergence of culture in wild chimpanzees: education by master-apprenticeship. In: Matsuzawa T, editor. Primate origins of human cognition and behavior. Tokyo: Springer. p 557-574.
McGrew WC. 1977. Socialization and object manipulation of wild chimpanzees. In: Chevalier-Skolnikoff S, Poirier FE, editors. Primate bio-social development. New York: Garland Publishing. p 261-288.

McGrew WC. 1979. Evolutionary implications of sex differences in chimpanzee predation and tool use. In: Hamburg DA, McCown ER, editors. The great apes. Menlo Park CA: Benjamin/Cummings. p 441-463.

McGrew WC. 1992. Chimpanzee material culture. Cambridge: Cambridge University Press.

McGrew WC. 2004. The cultured chimpanzee. Cambridge: Cambridge University Press.

McGrew WC, Marchant LF, Scott SE, Tutin CEG. 2001. Intergroup differences in a social custom of wild chimpanzees: the grooming hand-clasp of the Mahale Mountains. Curr Anthropol 42:148-153.

McGrew WC, Tutin CEG. 1978. Evidence for a social custom in wild chimpanzees? Man 13:234-251.

Möbius Y, Boesch C, Koops K, Matsuzawa T, Humle T. 2008. Cultural differences in army ant predation by West African chimpanzees? A comparative study of microecological variables. Anim Behav 76:37-45.

Nakamura M. 2002. Grooming-hand-clasp in MahaleM group chimpanzees: implication for culture in social behaviors. In: Boesch C, Hohmann G, Marchant LF, editors. Behavioural diversity in chimpanzees and bonobos. Cambridge: Cambridge University Press p 71-83.

Nakamura M, McGrew WC, Marchant LF, Nishida T. 2000. Social scratch: another custom in wild chimpanzees? Primates 41:237-248.

Nakamura M, Nishida T. 2006. Subtle behavioral variation in wild chimpanzees, with special reference to Imanishi's concept of kaluchua. Primates 47:35-42.

Nakamura M, Uehara S. 2004. Proximate factors of different types of grooming hand-clasp in Mahale chimpanzees: implications for chimpanzee social customs. Curr Anthropol 45:108-114.

Nishida T. 1988. Development of social grooming between mother and offspring in wild chimpanzees. Folia Primatol 50:109-123.

Nishida T. 1990. A quarter century of research in the Mahale Mountains: an overview. In: Nishida T, editor. The chimpanzees of the Mahale Mountains. Tokyo: University of Tokyo Press. p 3-35.

Nishida T. 2003. Individuality and flexibility of cultural behavior patterns in chimpanzees. In: de Waal FBM, Tyack PL, editors. Animal social complexity. Cambridge, MA: Harvard University Press, p 392-413.

Nishida T. 2012. Chimpanzees of the Lakeshore. Cambridge: Cambridge University Press.

Nishida T, Hiraiwa M. 1982. Natural history of tool-using behavior by wild chimpanzees in feeding upon wood-boring ants. J Hum Evol 11:73-99.

Nishida T, Mitani JC, Watts DP. 2004. Variable grooming behaviours in wild chimpanzees. Folia Primatol 75:31-36.

Nishida T, Wallauer W. 2003. Leaf-pile pulling: an unusual play pattern in wild chimpanzees. Am J Primatol 60:167-173.

Nishie H. 2011. Natural history of Camponotus ant-fishing by the M group chimpanzees at the Mahale Mountains National Park, Tanzania. Primates 52:329-342.

Panger MA, Perry S, Rose L, Gros-Louis J, Vogel E, Mackinnon KC, Baker M. 2002. Cross-site differences in foraging behavior of white-faced capuchins (Cebus capucinus). Am J Phys Anthropol 119:52-66.

Perry S, Baker M, Fedigan L, et al. 2003. Social conventions in wild white-faced capuchin monkeys. Curr Anthropol 
44:241-268.

Pusey AE. 1983. Mother-offspring relationships in chimpanzees after weaning. Anim Behav 31:363-377.

Pusey AE. 1990. Behavioral changes at adolescence in chimpanzees. Behaviour 115:203-246.

Rendell L, Whitehead H. 2001. Culture in whales and dolphins. Behav Brain Sci 24:309-382.

Schöning C, Humle T, Möbius Y, McGrew WC. 2008. The nature of culture: technological variation in chimpanzee predation on army ants revisited. J Hum Evol 55:48-59.

Tomasello M. 1994. The question of chimpanzee culture. In: Wrangham RW, McGrew WC, de Waal FBM, Heltne PG, editors. Chimpanzee cultures. Cambridge, MA: Harvard University Press. p 301-317.

van Lawick-Goodall J. 1970. Tool-using in primates and other vertebrates. In: Lehrman DS, Hinde RA, Shaw E, editors. Advances in the study of behavior, Volume 3. New York: Academic Press. p 195-249.

van Leeuwen EJC, Cronin KA, Haun DBM, Mundry R,
Bodamer MD. 2012. Neighbouring chimpanzee communities show different preferences in social grooming behaviour. Proc R Soci B 279:4362-4367.

van Schaik CP, Ancrenaz M, Borgen G, et al. 2003. Orangutan cultures and the evolution of material culture. Science 299:102-105.

Whiten A, Goodall J, McGrew WC, et al. 1999. Cultures in chimpanzees. Nature 399:682-685.

Whiten A, Horner V, de Waal FBM. 2005. Conformity to cultural norms of tool-use in chimpanzees. Nature 437:737-740.

Whiten A, Spiteri A, Horner V, Bonnie KE, Lambeth SP, Schapiro SJ, de Waal FBM. 2007. Transmission of multiple traditions within and between chimpanzee groups. Curr Biol 17:1038-1043.

Whiten A, van Schaik CP. 2007. The evolution of animal 'cultures' and social intelligence. Philos Trans R Soc B 362:603-620. 
TABLE I. Observed Number of GHC in Which Either of the Participants Was 15 Years Old or Younger

\begin{tabular}{|c|c|c|c|c|c|c|}
\hline \multirow{2}{*}{$\begin{array}{l}\text { Age of } \\
\text { the } \\
\text { younger }\end{array}$} & \multicolumn{2}{|c|}{ Male } & \multicolumn{2}{|c|}{ Female } & \multicolumn{2}{|c|}{ Total } \\
\hline & Observed \# & $\operatorname{Mean} \pm \operatorname{SD}(\mathrm{N})^{\mathrm{a}}$ & Observed \# & $\operatorname{Mean} \pm \operatorname{SD}(\mathrm{N})^{\mathrm{a}}$ & Observed \# & Mean \pm SD \\
\hline $0-3$ & 0 & $0.00 \pm 0.00(46)$ & 0 & $0.00 \pm 0.00(73)$ & 0 & $0.00 \pm 0.00$ \\
\hline 4 & 2 & $0.29 \pm 0.76(7)$ & 0 & $0.00 \pm 0.00$ & 2 & $0.08 \pm 0.41$ \\
\hline 5 & 2 & $0.20 \pm 0.63(10)$ & 3 & $0.19 \pm 0.40(16)$ & 5 & $0.19 \pm 0.49$ \\
\hline 6 & 12 & $1.09 \pm 2.77(11)$ & 27 & $1.50 \pm 4.23(18)$ & 39 & $1.34 \pm 3.70$ \\
\hline 7 & 13 & $1.86 \pm 4.91(8)$ & 1 & $0.06 \pm 0.24$ & 14 & $0.58 \pm 2.65$ \\
\hline 8 & 19 & $2.38 \pm 2.07$ (8) & 2 & $0.15 \pm 0.38$ & 21 & $1.00 \pm 1.67$ \\
\hline 9 & 57 & $5.18 \pm 8.75$ & 5 & $0.38 \pm 0.96(13)$ & 62 & $2.58 \pm 6.30$ \\
\hline 10 & 24 & $3.43 \pm 3.74(7)$ & 3 & $0.21 \pm 0.58(14)$ & 27 & $1.29 \pm 2.61$ \\
\hline 11 & 12 & $1.20 \pm 2.10(10)$ & 1 & $0.08 \pm 0.29(12)$ & 13 & $0.59 \pm 1.50$ \\
\hline 12 & 46 & $4.27 \pm 5.78(11)$ & 5 & $0.67 \pm 1.76(15)$ & 51 & $2.19 \pm 4.29$ \\
\hline 13 & 41 & $5.33 \pm 7.14(9)$ & 11 & $1.56 \pm 1.94(9)$ & 51 & $3.44 \pm 5.44$ \\
\hline 14 & 24 & $2.40 \pm 3.41(10)$ & 19 & $1.83 \pm 2.76(12)$ & 44 & $2.09 \pm 3.01$ \\
\hline 15 & 43 & $5.33 \pm 6.42(9)$ & 11 & $1.45 \pm 1.81(11)$ & 54 & $3.20 \pm 4.80$ \\
\hline Total & 295 & & 88 & & 383 & \\
\hline
\end{tabular}

TABLE II. Ages at First Observed GHC with Mother

\begin{tabular}{|c|c|c|c|c|}
\hline $\begin{array}{l}\text { Name of } \\
\text { offspring }^{\text {a }}\end{array}$ & Sex of offspring & $\begin{array}{l}\text { Age at first observed } \\
\text { GHC }\end{array}$ & Initiator $^{b}$ & Holder $^{c}$ \\
\hline $\mathrm{XM}$ & male & $4 \mathrm{yr} 4 \mathrm{mo}$ & mother & mother \\
\hline$F V$ & female & 5 yr 3 mo & mother & mother \\
\hline$A Q$ & female & 5 yr $10 \mathrm{mo}$ & mother & both \\
\hline$I M$ & female & 6 yr 1 mo & mother & offspring \\
\hline MC & male & 6 yr 2 mo & mother & mother \\
\hline$J D$ & female & 6 yr $7 \mathrm{mo}$ & not confirmed ${ }^{\mathrm{d}}$ & not confirmed ${ }^{\mathrm{d}}$ \\
\hline$A T$ & female & 6 yr 8 mo & not confirmed ${ }^{\mathrm{d}}$ & not confirmed ${ }^{\mathrm{d}}$ \\
\hline IV & female & 8 yr 7 mo & not confirmed $^{\mathrm{d}}$ & not confirmed ${ }^{\mathrm{d}}$ \\
\hline
\end{tabular}

GHC: grooming hand-clasp.

a Only those who had been observed since birth and were observed to perform GHC at least once with the mother are shown here.

b "Initiator" means the one first raised a hand for GHC.

c “Holder" means the one who grasped the other's wrist with the palm. When both individuals grasped the other's wrist, it was judged "both.” There was no palm-to-palm type [sensu McGrew et al., 2001] where palm and palm were clasped.

d "Not confirmed" means we could not record initiator and/or holder because the duration of GHC was too short to confirm them or because the observation was made during the focal follow of other individuals.

TABLE III. Comparison of the Earliest Ages of Performance of Some Cultural Behaviors

\begin{tabular}{|c|c|c|c|}
\hline Cultural Behaviors & $\begin{array}{l}\text { Research } \\
\text { site }\end{array}$ & Earliest Age & Source \\
\hline \multirow[t]{2}{*}{ Ant-dipping } & Bossou & 2 yr 0 mo & Humle et al., 2009b \\
\hline & Gombe & 3 yr $10 \mathrm{mo}$ & McGrew, 1977 \\
\hline \multirow[t]{2}{*}{ Ant-fishing } & Mahale M & 2 yr 5 mo & Nishie, 2011 \\
\hline & Mahale K & 2 уг 8 mo & Nishida \& Hiraiwa, 1982 \\
\hline Termite-fishing & Gombe & 2 yr 6 mo & Lonsdorf, 2005 \\
\hline Coula nut-cracking & Tаї & $3 \mathrm{yr}$ & Boesch \& Boesch-Achermann, 2000 \\
\hline Elaeis nut-cracking & Bossou & 3 yr 6 mo & Inoue-Nakamura \& Matsuzawa, 1997 \\
\hline Panda nut-cracking & Таї & $5 \mathrm{yr}$ & Boesch \& Boesch-Achermann, 2000 \\
\hline GHC with mother & Mahale M & 4 yr 4 mo & This study \\
\hline \multirow[t]{2}{*}{ GHC with non-kin } & Mahale M & 5yr 4mo (orphan) & This study \\
\hline & & 9yr 0mo (non-orphan) & \\
\hline \multirow[t]{2}{*}{ GHC with adult male } & Mahale M & 9 yr (orphan) & This study \\
\hline & & 11 yr 5 mo (non-orphan) & \\
\hline
\end{tabular}


Age in years

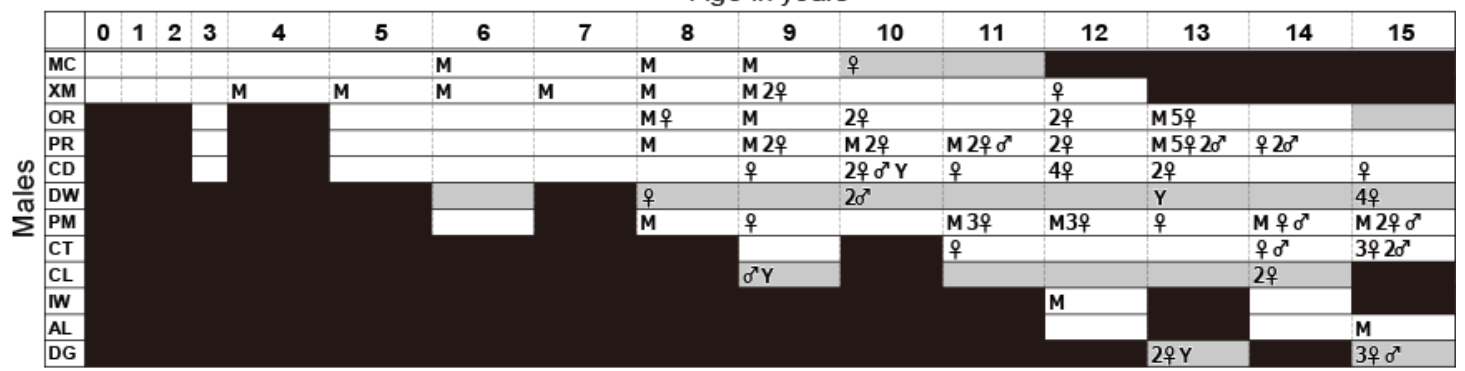
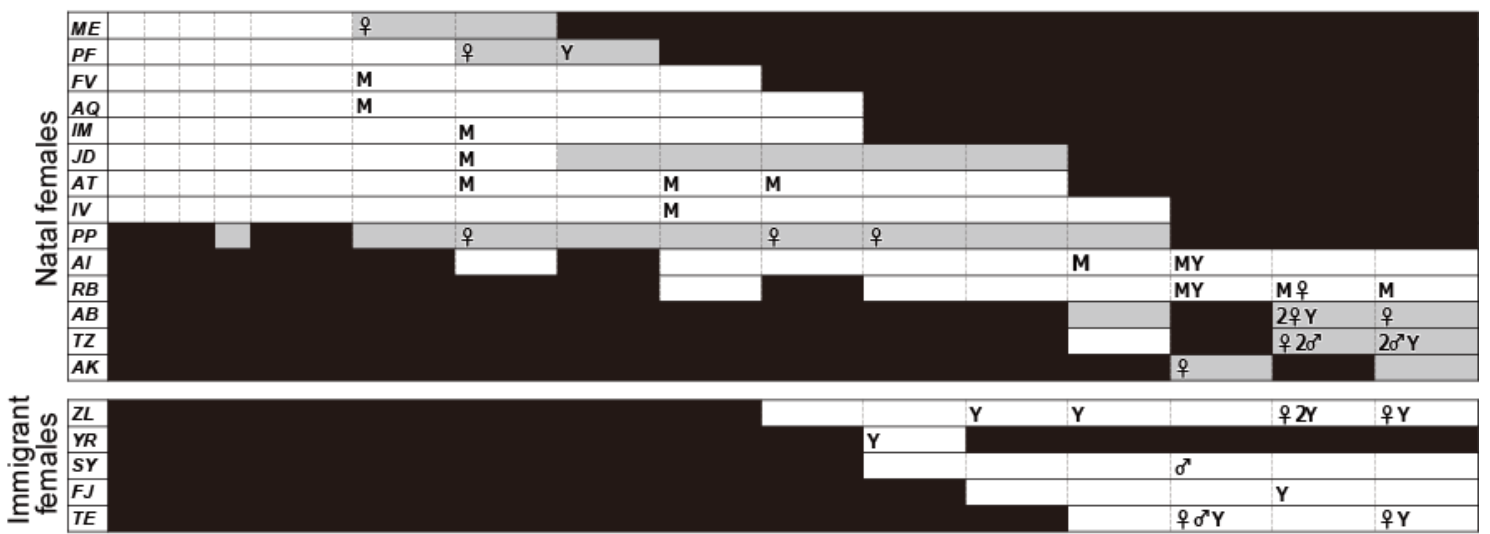

Fig. 1. One-zero frequency for different types of grooming hand-clasp (GHC) partners of youngsters (15 years old and under) at a given age. Only those who were observed to perform GHC at least once during the study period are listed here. "M" = mother; " $P$ " = female other than the mother (adults and adolescents are combined here because the latter were partners only in a few cases); " $\mathrm{O}$ " =adult male; "Y" = adolescent male. Numerals before these characters mean the number of partners in the class. For example, "M 2 " in the 9 -year column of XM means that he was observed to perform GHC at least once each with his mother and other two different females when he was 9 years old. A black cell indicates that the individual was not available at the given age including lack of field observation and death/disappearance (e.g., MC's cells after 12 years old are black because he was 11 years old at the end of the study, and DG's cells before 12 years old are black because he was already 13 at the onset of the study). A light gray cell indicates that the individual's mother was already dead (thus, he/she was orphaned) at that age. Immigrant females' cells are not painted in gray because we do not have information on their mothers. A white or gray blank cell indicates that the individual was available but not observed to do any GHC at that age. Ages of immigrant females were estimated.

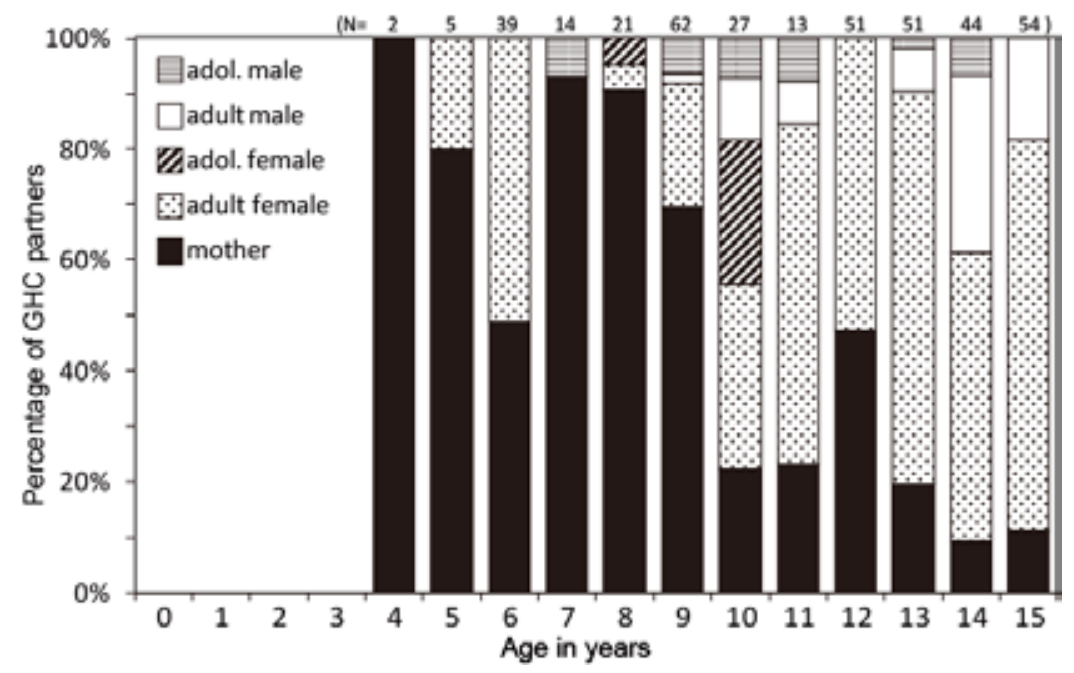

Fig. 2. Age change in the percentages of grooming hand-clasp (GHC) partners. Numbers shown at the top of bars are numbers of observed GHC events for the age groups. 


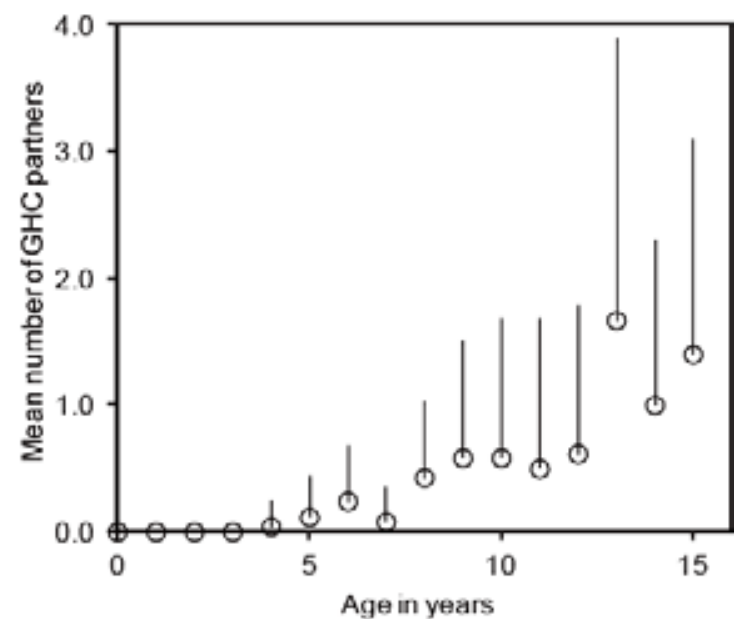

Fig. 3. Mean number of grooming hand-clasp (GHC) partners per individual by age. A circle indicates mean of individuals of both sexes combined and a vertical bar indicates standard deviation.

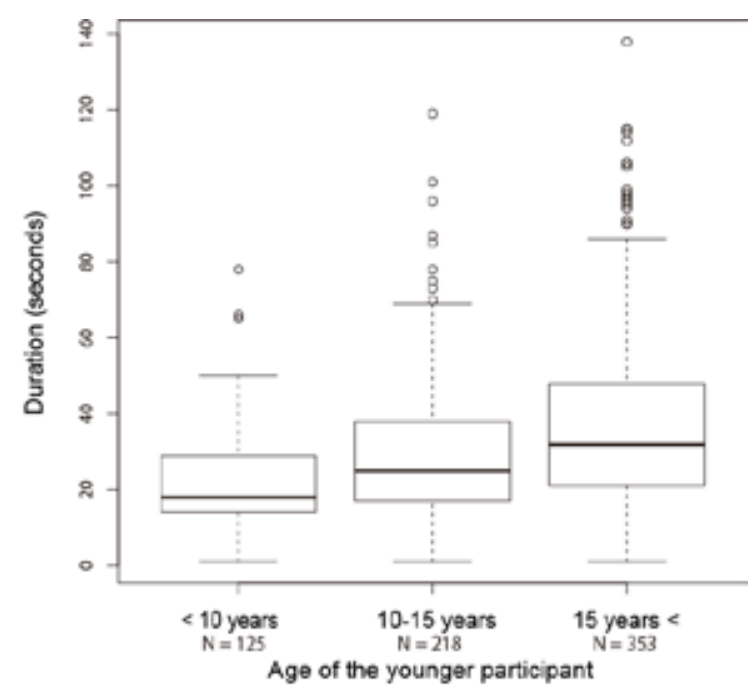

Fig. 4. Duration of grooming hand-clasp (GHC) by younger participant's age. The band in the middle shows median, bottom and top of the box show lower and upper quartiles, respectively, and whiskers indicate 1.5 interquartile range. Small circles are outliers outside this range. 

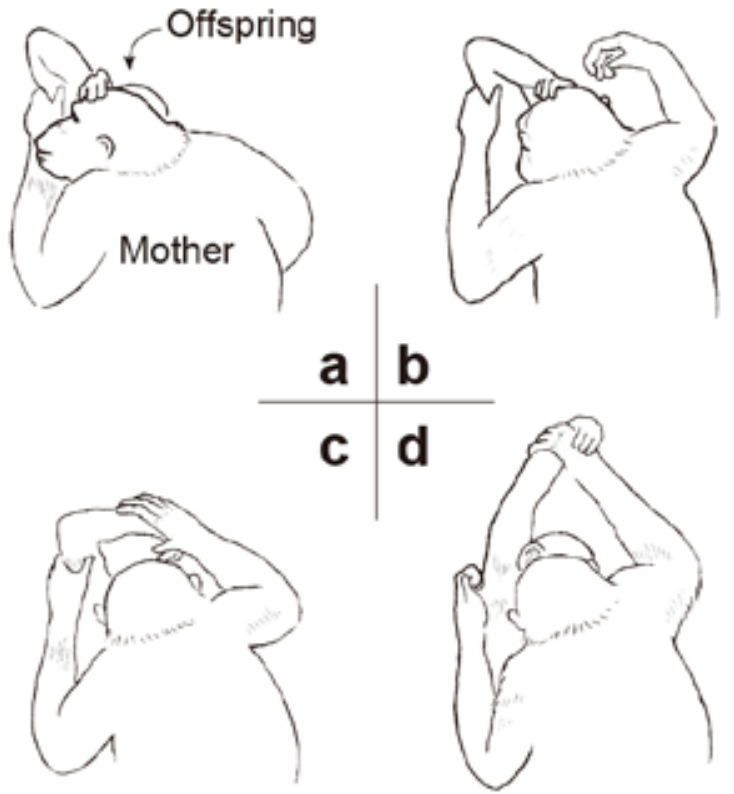

Fig. 5. An example of molding behavior toward an offspring by its mother. (A) Mother puts her left hand under offspring's upper right arm and begins to raise her right hand. (B) The mother continues to lift offspring's right arm with her left hand, at the same time her right hand moves toward offspring's right wrist. The offspring's right arm is not yet stretched. (C) The mother grasps the offspring's right wrist with her right hand and then pulls it upward. (D) The mother begins to groom offspring's underarm with her left hand, and the offspring also grooms her, thus, the posture of GHC has been completed. Drawn from video footage recorded on August 30, 2000. 